\title{
DAMAGE CRITERIA IN ROUNDHEADS WITH A SINGLE LAYER OF CUBIPOD ARMOR UNITS
}

\author{
J. Sande ${ }^{1}$, E. Peña ${ }^{1}$, E. Maciñeira
}

The present paper covers the analysis of damage in a single-layer roundhead armored with Cubipods. This study was carried through physical model tests. Firstly, the analysis of the damage in these structures has not been an intensive studied topic. It is normally defined when a piece doesn't contribute in the stability on the single layer armor and, due to, a new damage criteria was proposed. In addition, vertical and sectorial size of active zone was defined. It could be possible defined three different phases in the evolution of damage due to the homogenous behavior for the roundhead. The most damage sector is $90-135^{\circ}$, and the neighbors, $45-90^{\circ}$ and $135-180^{\circ}$, but damage in $45-90^{\circ}$ is greater in frequency and value. Also, the dimensionless parameters of roundhead size $\left(\mathrm{R}_{\mathrm{n}}, \mathrm{R} / \mathrm{H}\right.$ and $\left.\mathrm{R} / \mathrm{L}\right)$ are involved in this phenomenon. Besides, the vertical size of active zone is defined in $\pm 1.5 \mathrm{H}_{\mathrm{s}}$ since sea water level (SWL), being the wave steepness is the principal parameter involved. It was proposed two level of damage: start of damage (D [\%] $=0.4$ ) and failure (D [\%] =11). Finally, it has been measure the reserve of stability. It is defined like the percentage of wave that the roundhead is able to resists between 2 levels of damage. This parameter allows analyzes the rigid behavior of the roundhead single layer armor. The value of this parameter, except one case, is RE [\%] $=9$. It was conclude that wave steepness is a relevant parameter, when it increased the reserve is reduces.

Keywords: Damage criteria, single-layer, Roundhead, Cubipod, sea-level-radius.

\section{INTRODUCTION AND OBJECTIVES}

Breakwater roundheads are a critical part on design of these structures. Initially, it was found that it had a rigid behavior in comparison with the trunks. For that reason, some useful guidelines propose increase the weight of the armors elements in this part of the breakwaters. Currently there are two publications that are worldwide references on roundheads design, "Coastal Engineering Manual, CEM (2002)" and "The rock manual, CIRIA/CUR/CETMEF (2007)". They include the main researches made in which it was defined the variables more relevant in the roundhead stability.

Nevertheless some studies over roundhead stability and damage location are not included in these publications, (Maciñeira and Burcharth, 2016, Comola, et al., 2014, Sande, et al., 2014, Van Gent and Van der Werf, 2010, Vidal, et al., 1989). These works has reflected the influence of new variables, in particular, the relative size of the roundheads. They studied this variable through three dimensionless parameters:

- $\quad \mathrm{R}_{\mathrm{n}}$ : Roundhead radius at SWL between the $\mathrm{D}_{\mathrm{n}}$ of the pieces (Maciñeira, 2005)

- $\mathrm{R} / \mathrm{H}$ : Roundhead radius at SWL between the wave height (Van der Werf 2010)

- R/L: Roundhead radius at SWL between the wave length (Vidal et al. 1989)

On the other hand, new armor units have been developed in order to optimize breakwater designs. These units can resist the waves in three different ways: their own weight (massive pieces: cubes, Antifer, Cubipod), interlocking (bulky pieces: X-Bloc, CoreLoc ...) and, finally, units resisting by the weight and the interlocking (Tetrapod, Dolo...). In addition, another characteristic of these pieces is the placement can be random or regular.

Initially the design of these pieces was made for armors with two or three layers, because they were the most commonly used. The developments of single-layer armors were made in order to optimal design and reduce the total cost of construction. But, they require a detailed analysis of the damage and their evolution, because the behavior is more rigid than the two-layer armors.

The Cubipod is a massive concrete armour unit created to be used in roundheads and trunks armors through single and double layer. This unit is similar to a cube except that it features protrusions on each face. It was designed to prevent heterogeneous packing densities as well as to increase the friction with the filter layer (Gomez-Martin \& Medina, 2007; Medina \& Gómez-Martín, 2015). Several studies were made in different laboratories to analyse the stability of Cubipod in the trunk with two and one layer. The stability of roundhead (Burcharth, et al., 2010; Lomonaco, et al., 2009) was also studied with small-scale models, but only double-layer armours were studied initially (Sande et al. 2014).

The study of damage evolution is fundamental to know the behavior of the breakwaters, and, through it, to define the design points. The classic methodologies to measure damage $\left(S, N_{\text {od }}\right.$ and $D$, which are described in CEM (2002)) don't reflect the real behavior of the single-layer armor. They have been grounded on two approaches. The first one is to quantify in a section the number of pieces moved. These methodologies account one piece movement it moves more than $1 \mathrm{D}_{\mathrm{n}}$. Thus, they don't allow measure the settlements and analyze the first phases of damage, which are very important in breakwaters with a rigid behavior. Currently, Gomez-Martin (2015) has presented a new methodology

\footnotetext{
${ }^{1}$ Water and Environmental Engineering Group (GEAMA), Civil Engineering School, University of A Coruña, Campus de Elviña, A Coruña, 15701, Spain
} 
for the analysis and detection of settlement and heterogeneous packing densities through virtual meshes.

The evolution of damage in the breakwater roundheads have a different behavior than the trunks. The damage is normally located in a critical sector which is consequence of the direction of wave fronts respect to the roundhead (Figure 1).

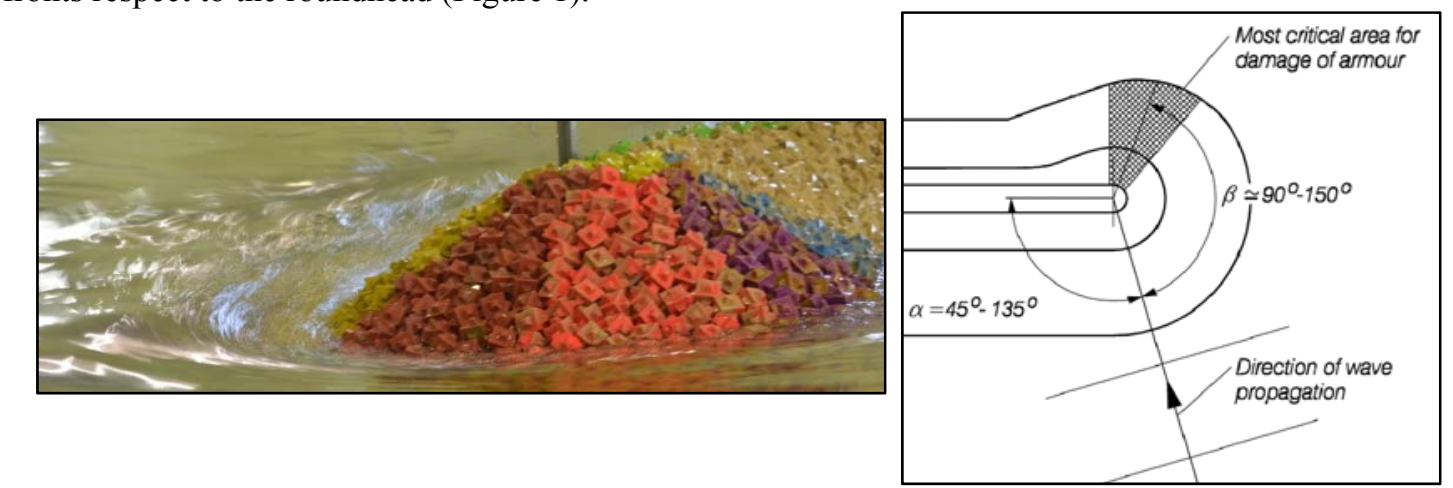

Figure 1. Left: Flow over roundhead. Right: Damage location in the roundhead, CEM (2002).

Berenguer and Baonza (1999), Lomonaco et al. (2009) and Maciñeira and Burcharth (2016) in two layer system, measured the damage in the critical sector as the number of units displaced in comparison with the total number of units, D [\%]. Van Gent and Luis (2013) in a single-layer system quantified it as $\mathrm{N}_{\mathrm{od}}$, and, Holfland and Van Gent (2016) analyzed the movements of the pieces, focusing on the settlements.

On the other hand, the damage stages represent specific points of the damage curves. Normally, the reference book (CEM, 2002), suggested four stages: rocking, start of damage, star of destruction, and failure. These cannot be directly applied to single-layer system, because they are defined for twolayer armors, and these are more flexible. For example, destruction is defined by the moment which the filter is exposed directly to the waves. But, in single-layer armor would occur when the first piece of the section fell. Thus, the definition of movement requires a detailed analysis because the evolution of damage is different, Sande et al. (2014).

In addition, single-layer systems need the study of settlements, which today are not considered as levels of damage. In order to measure it different techniques are used. The photogrammetric techniques has been applied with cubic pieces by Van Gent and Luis (2013) and Holfland and Van Gent (2016), Gomez-Martin (2015) for Cubipods, and in the case of Xbloc and Acropodo by Muttray and Reedijk (2009). Another recently technique used to analyze these phenomena accurately in Cubipods is the laser LiDAR 3D scan (Puente et al. 2014).

\section{EXPERIMENTAL CAMPAIGN}

\section{Experimental facilities and equipment}

The experimental campaign was conducted in a wave tank (Figure 2) at CITEEC (R+D Centre in Building and Civil Engineering of the Universidade da Coruña, Spain), where both 2D and 3D tests can be reproduced. The full-basin has dimensions of $33 \times 34 \times 1.2 \mathrm{~m}$. The wave basin is divided in two nearly half parts. First one has dimensions of $33 \times 16 \times 1.2 \mathrm{~m}$, and bathymetry with a $1.85 \%$ slope. This bathymetry allows different locations for coastal structures closely to each particular case. Second one has dimensions of $33 \times 12 \times 1.2 \mathrm{~m}$ and plane bottom. To avoid reflections dissipative beaches with a parabolic profile are located in all boundaries. Currently, the basin is equipped with both, unidirectional and multidirectional wave generation systems, but the experimental campaign was done using with the unidirectional one developed by Delft Hydraulics provide with unidirectional wave paddles (wide $4 \mathrm{~m}$ ). 

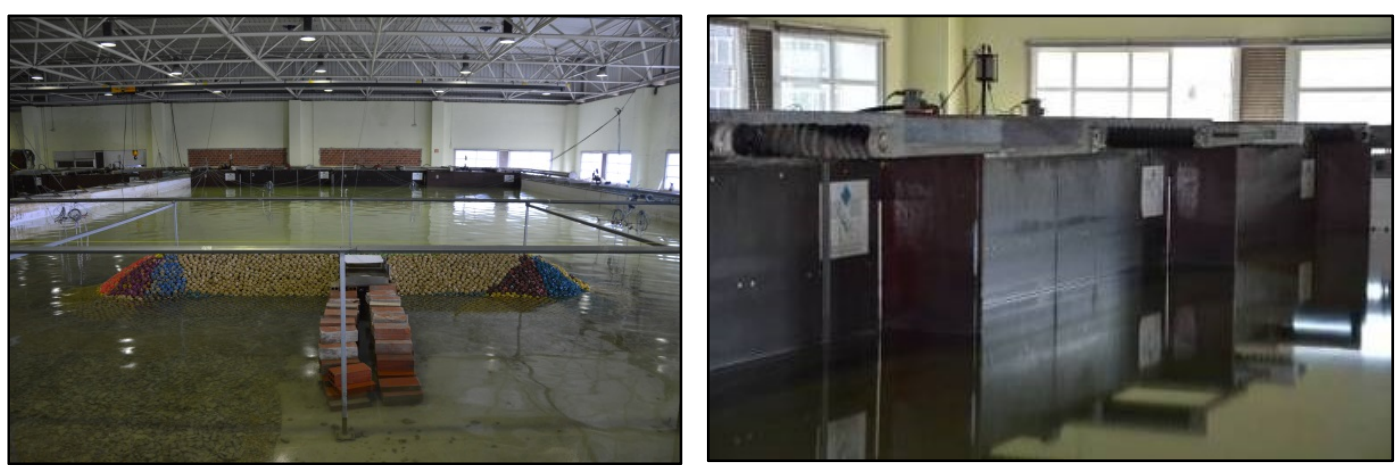

Figure 2. Left: Model tested at the CITEEC wave tank. Right: Unidirectional wave paddles.

A detailed work was carried out for the calibration of the basin and the propagation of the waves. First, the correct synchronization of the wave generation paddles has been studied, to avoid unwanted lateral activity. In addition, the incident and reflected waves were studied using LASA software, Medina (2001). The reflections of the wave tank were determined without the model, where the maximum values in the area of wave generation reached to values between 3 and $11 \%$, resulting in energy coefficients less than $1.2 \%$. Furthermore, the shoaling was analyzed obtaining values close to theoretical ones (assuming wave linear theory).

The experimental equipment selected in order to measure the wave height was the conductive level probes, witch measure the incident and generated wave. In the experiments there were collocated 10 gauges to measure the wave height with an accuracy of $0.3 \mathrm{~mm}$.

Furthermore, in order to measure the armor damage in the model, photographs in the same position and in all sectors were taken using an adjacent structure. These photographs allowed us to obtain cells in the active zone of each sectors of the roundhead to determine the evolution of porosity. On the other hand the roundheads were divided in $45^{\circ}$ sectors, using pieces of different colors to measure damage as the number of displaced units (Figure 3).

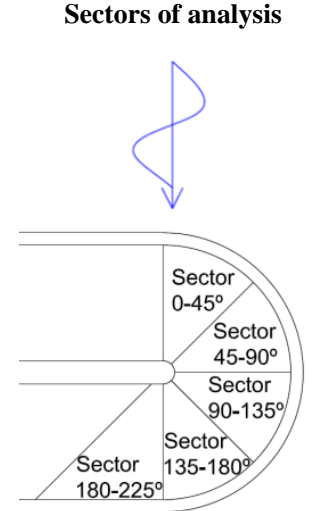

Sector $90-135^{\circ}$

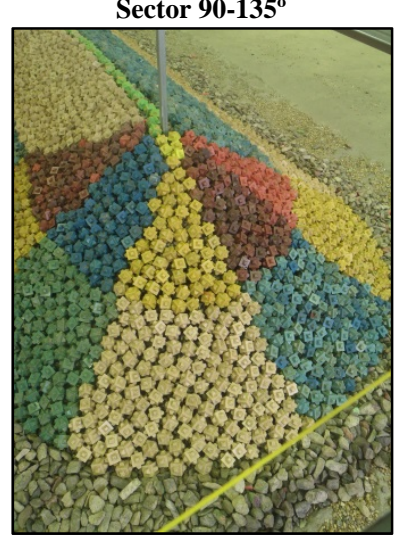

Sector $0-45^{\circ}$

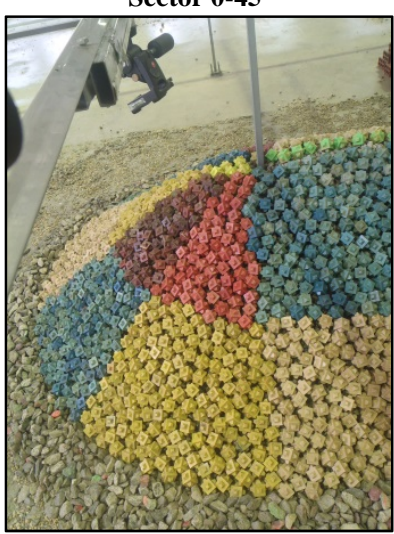

Sector $135-180^{\circ}$

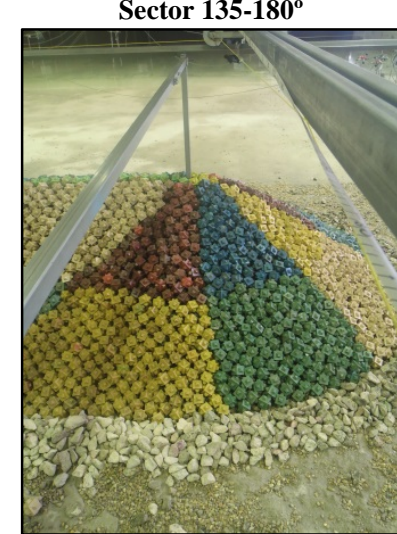

Sector $45-90^{\circ}$

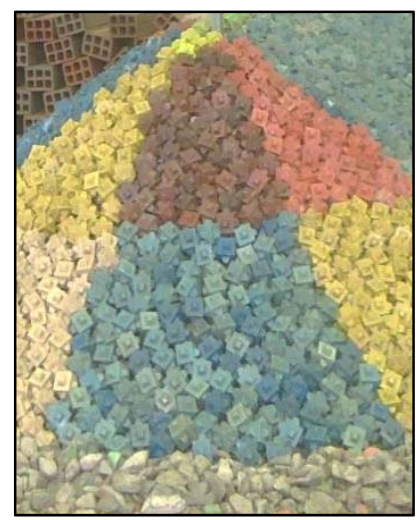

Sector $180-225^{\circ}$

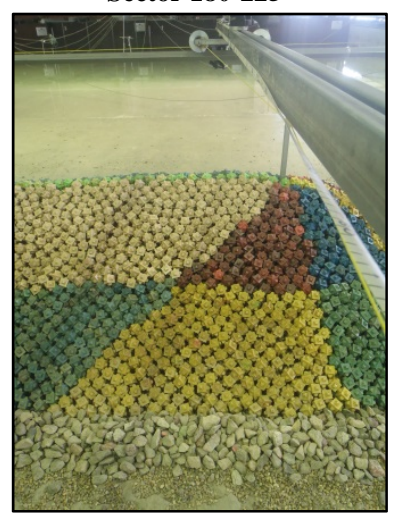

Figure 3. Photograph in each sector tested. 


\section{Description of the model}

The breakwaters tested were formed by two roundheads with different radius connected by a trunk of $4 \mathrm{~m}$ length. To study a large range of radius at SWL, there were conducted three models (designed A, $\mathrm{B}$ and $\mathrm{C}$ ), tested with different water depths and wave conditions. The three models had two similar significant features in the design: (1) the initial armor porosity $p=42 \%$ and (2) the slope $H / V=1: 1.5$.

The trunk and the smaller roundhead had the same section. Therefore, it was necessary to make a transition between the trunk and the larger roundhead of the model (Figure 4). Furthermore, a structure was placed in the rear part of the breakwater to absorb diffracted waves to avoid unwanted effects in the back of the model.

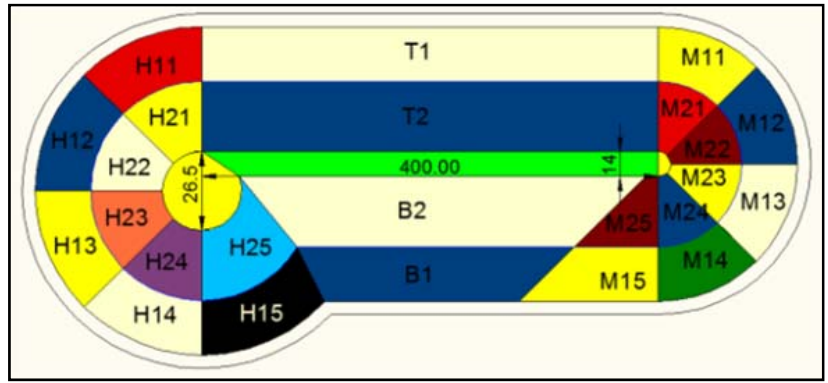

Figure 4. Aerial view of the model.

The model A have the largest radios tested. The height of this model was $72 \mathrm{~cm}$ and the radius of the roundheads were $\mathrm{R}[\mathrm{cm}]=134.5$ and $\mathrm{R}[\mathrm{cm}]=158.5$ in the base, being $\mathrm{R}[\mathrm{cm}]=11.15$ and $\mathrm{R}[\mathrm{cm}]$ $=35.15$ in the upper part.
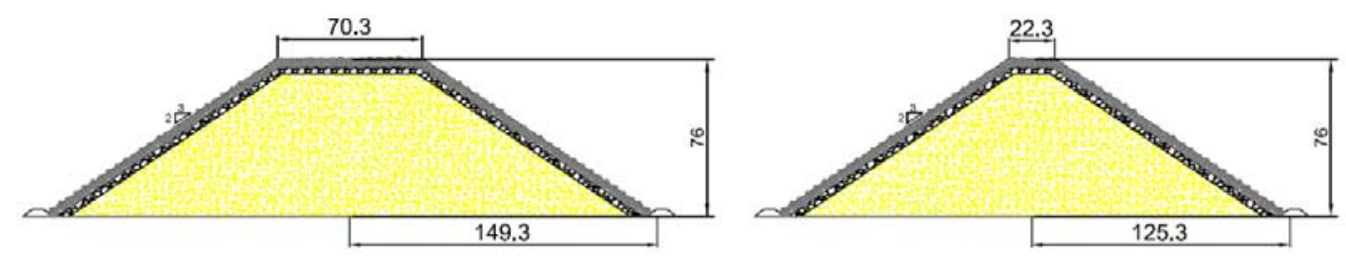

Figure 5. Roundhead and trunk sections in the model A. Dimensions in $\mathrm{cm}$.

The model $\mathrm{B}$, had a height of $60 \mathrm{~cm}$ and radius of $\mathrm{R}[\mathrm{cm}]=99.3$ and $\mathrm{R}[\mathrm{cm}]=100.8$ at the base, while in the upper part $\mathrm{R}[\mathrm{cm}]=7$ and $\mathrm{R}[\mathrm{cm}]=13.25$.
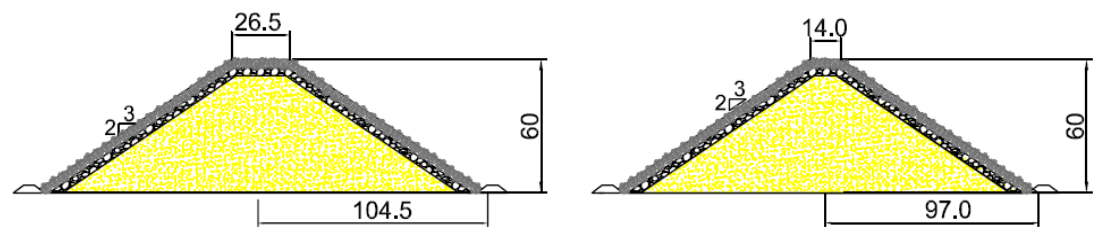

Figure 6. Roundhead and trunk sections in the model B. Dimensions in $\mathrm{cm}$.

Finally, the model $\mathrm{C}$ consisting of a height of $65 \mathrm{~cm}$ and the radius of the roundhead $[\mathrm{cm}]=99.3$ and $R[\mathrm{~cm}]=100.8$ at the base, being $R[\mathrm{~cm}]=1.8$ and $R[\mathrm{~cm}]=6.45$ In the coronation.
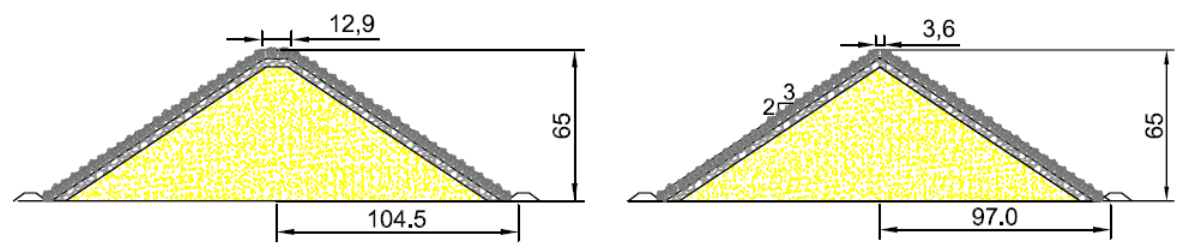

Figure 7. Roundhead and trunk sections in the model C. Dimensions in $\mathbf{c m}$.

The rubble mound breakwater model was formed by a core $\left(\mathrm{D}_{\mathrm{n} 50}=0.7 \mathrm{~cm}\right)$ and a two-layer filter $\left(\mathrm{D}_{\mathrm{n} 50}=1.7 \mathrm{~cm}\right)$. The armor was formed by a Cubipod single-layer resin units $\left(\mathrm{W}=128 \mathrm{~g}, \mathrm{D}_{\mathrm{n} 50}=3.82 \mathrm{~cm}\right.$, mass density=2.28 g/cm3). 


\section{Experimental conditions}

The selected scale for the study was $\lambda=1 / 50$ according to the Froude similarity. The stability of the roundhead was studied by a series of tests increasing progressively the significant wave height and keeping constant the Iribarren number.

Waves reproduced were unidirectional, irregular (JONSWAP, $\gamma=3.3$ ) and the incidence of the waves was perpendicular to the trunk. The initial significant wave height was $\mathrm{H}_{\mathrm{s}}=8 \mathrm{~cm}$ and was increased in $1 \mathrm{~cm}$ in each step until the roundhead failure. 1000 waves were tested for each $\mathrm{H}_{\mathrm{s}}$ reproduced in two separates trains of 500 wave each one.

In order to analyze the importance of the radio at SWL roundhead, different water levels were tested in models, $\mathrm{h}[\mathrm{cm}]=32,35,40$ and 48 and four Iribarren numbers $\left(\mathrm{I}_{\mathrm{rp}}=3.5,4.0,5.0\right.$ and 6.0) for each water level. A total of 44 roundhead stability tests were completed from no damage to destruction ranging a radius at SWL which ranging between the $27-100 \mathrm{~cm}$ in 13 different roundhead radius at SWL.

\section{RESULTS AND DISCUSSION}

\section{Damage evolution}

Three different phases were defined in the Cubipods movements due to their homogenous behavior. Initially, the first movements are located under sea water level (SWL), (phase I Figure 8-I). The holes generated produce a loss of support in the contiguous pieces. In consequence, the pieces located in the emerged zone move to the submerged in order to refill the holes, (phase II Figure 8-II). Finally, the failure was produced in the emerged zone of the roundhead in the phase III, (Figure 8-III)
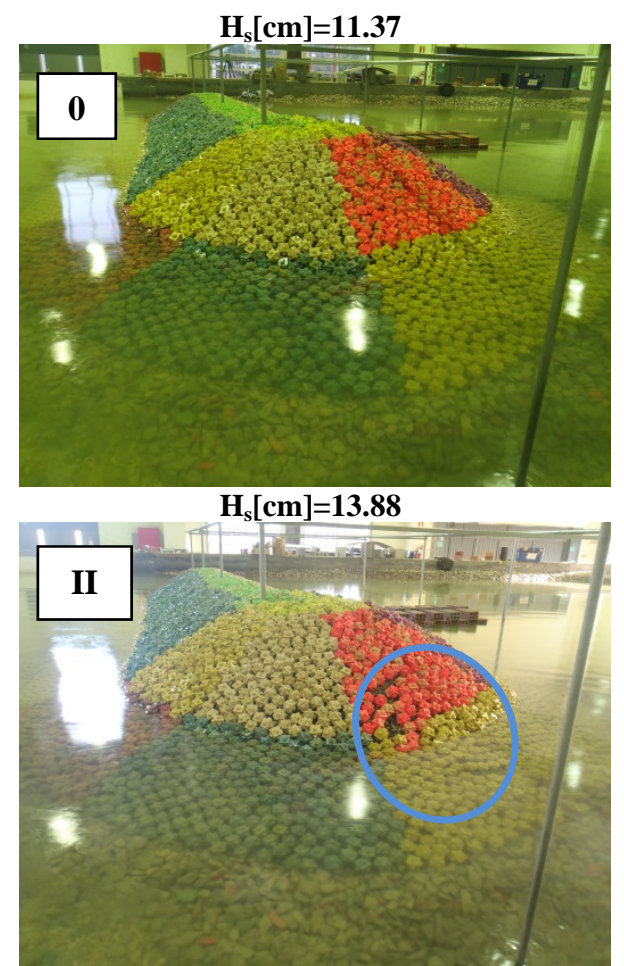

Figure 8. Damage evolution. $H_{s}[\mathrm{~cm}]=11.37$, phase $0 . H_{s}[\mathrm{~cm}]=12.04$, phase $I . H_{s}[\mathrm{~cm}]=13.88$, phase II and $H_{s}$ $[\mathrm{cm}]=15.46$ phase III.

The initial movements occur always in the $90-135^{\circ}$. The following were produced in this and in the neighbors $\left(45-90^{\circ}\right.$ and $\left.135-180^{\circ}\right)$. It could be observed the typologies of damage:

- Cubipods move in critical sector 90-135

- Cubipods move between $45-135^{\circ}$

- Cubipods move between $45-180^{\circ}$

The first typology was produced in 12 of 45 roundheads tested, and the second one was the typology more reproduced, 19 of 45 . The characteristic of the roundheads for these two typologies cover the complete range of values analyzed (radius at SWL and Iribarren number). Finally, Cubipods 
move in $45-180^{\circ}$ was produced in 7 of 45 . It was observed that these movements occur in roundheads with smaller radius at SWL.
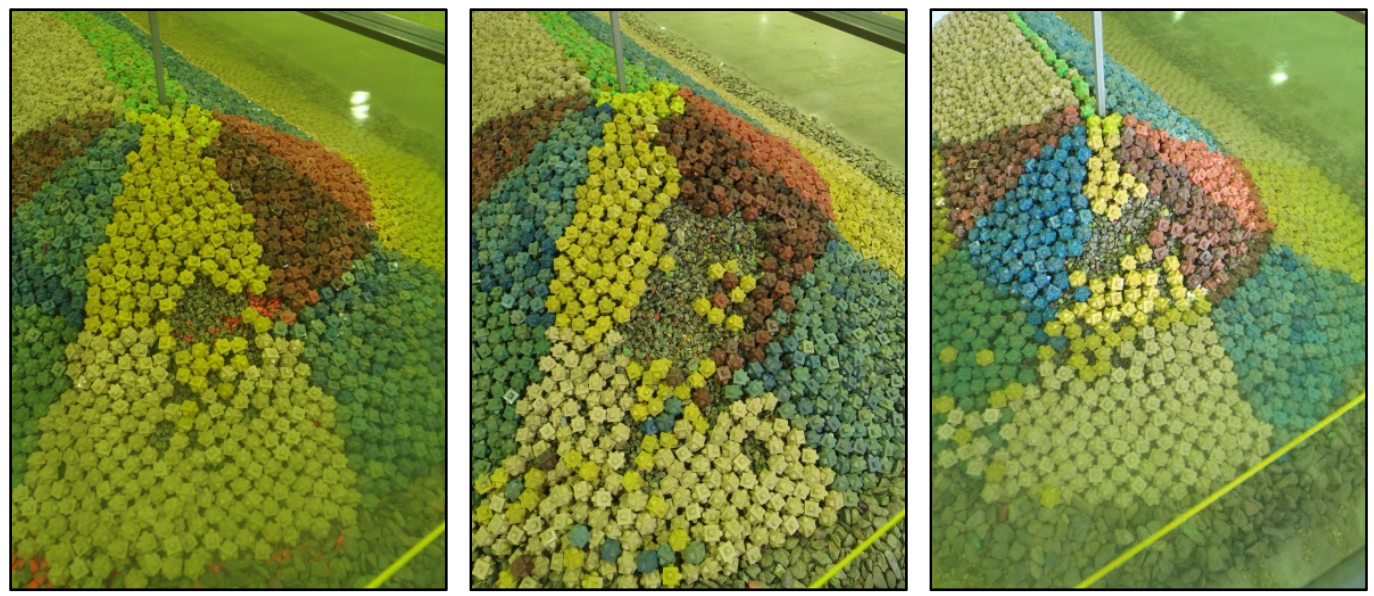

Figure 9. Damage typologies. Left: Cubipods moves in critical sector 90-135 . Medium: Cubipods moves between $45-135^{\circ}$. Right: Cubipods moves between $45-180^{\circ}$.

\section{Porosity}

Porosity was measured counting the number of Cubipods in the emerged and submerged zone for all the wave heights tested. The porosity in the emerged zone always increases during a test. But, there were detected two different patrons in the submerged zone porosity evolution.

First patron is the same that in the emerged zone, it increases during the test. Nevertheless, the second one consists on an initially increase due to the firsts Cubipods fallen, but after this, it reduces to consequence of the moves in the second phase of the evolution of damage (Figure 10).

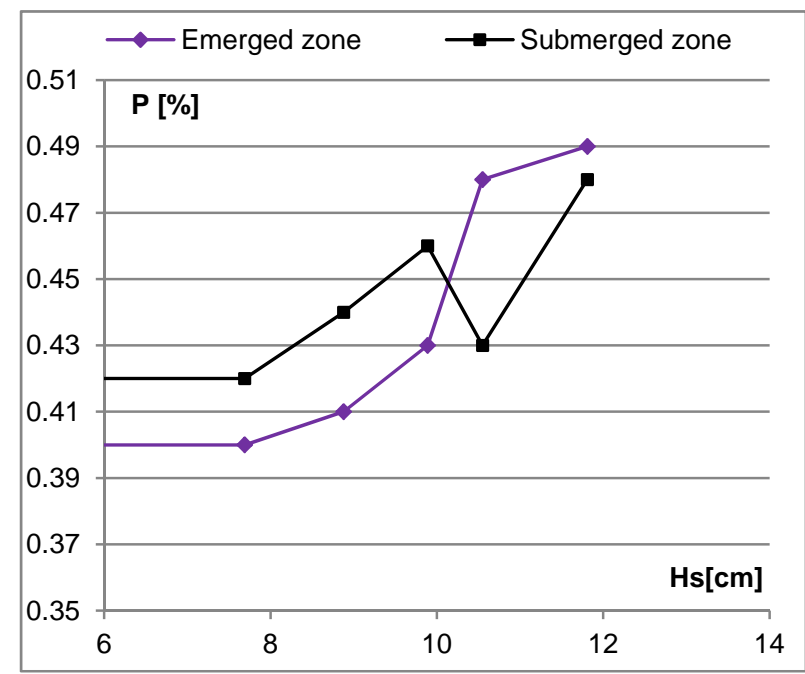

Figure 10. Porosity evolution.

\section{Measure of Damage}

Single layer armor damage is not a concept well defined, currently doesn't exit a general criterion to measure and quantify it. CEM (2002) defined for double layer armors, the moment of one piece didn't contribute to stability it is moves more than one nominal diameter. In addition, failure is defined as filter layer exposed.

Previously, it was observed that one Cubipod can move more than $1 \mathrm{D}_{\mathrm{n}}$, and it could continue contributing to stability of the roundhead. It was observed that only a piece do not contribute to the stability in the following cases:

1. If it moves to the second layer or out of the section (yellow and orange Cubipod, red circle in Figure 11)

2. If it moves out of its sector (red Cubipods, black circle in Figure 11) 


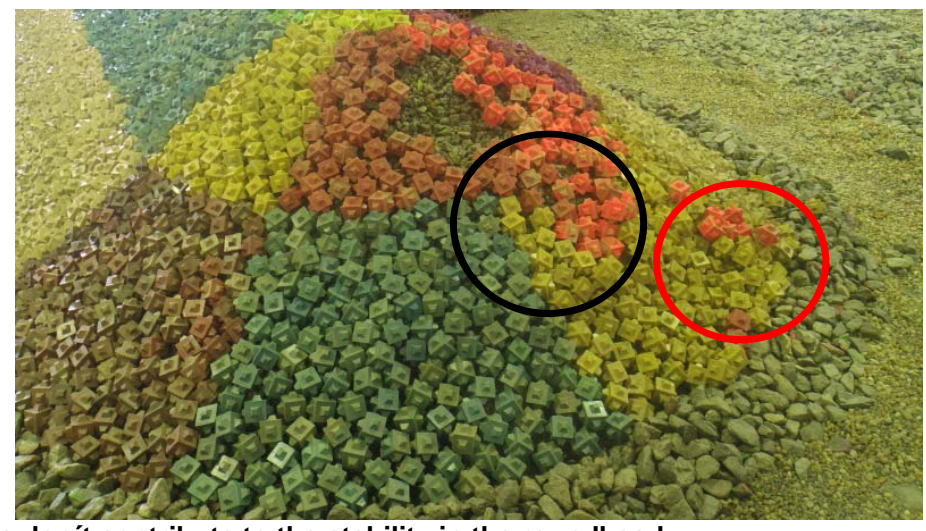

Figure 11. Cubipods don't contribute to the stability in the roundhead.

Once the Cubipods movement is defined, it was studied different methodologies to measure the damage. The most used methodologies (, $\mathrm{N}_{\text {od }}$ and $\mathrm{D}$ ) are defined in CEM, (2002). The $\mathrm{S}$ parameter measure the damage in a section through the delimitation of the eroded profile, but it is not possible to apply in the roundhead, because the movements are normally located downstream. Secondly, the $\mathrm{N}_{\text {od }}$ parameter is not possible to use in roundheads, (Berenguer \& Baonza, 1999). The virtual mesh (Gómez-Martín, 2015) measures the damage and correlates it with the porosity evolution. This method accepts that one Cubipod moved more than $1 \mathrm{D}_{\mathrm{n}}$ continue contributing to stability, but it is not possible to apply this methodology in this study, due to the pattern of porosity evolution. Finally, the selected methodology to measure damage it is the volumetric damage, D [\%]:

$$
D_{i}=\frac{N_{i}}{N_{0 i}} 100
$$

Where $\mathrm{N}_{\mathrm{i}}$ is number of Cubipods in the test $\mathrm{i}$ and $\mathrm{N}_{0 \mathrm{i}}$ is the initial number of the Cubipods.

It was verified that the settlements in the roundhead are not significant before the first Cubipod it fallen. Nevertheless, they are important from the first Cubipod fallen, but, these are measures with the selected technique. Like consequence damage and porosity have the following relation:

$$
N_{0 i}=\frac{A_{i}\left(1-P_{0 i}\right) D_{n} K_{\Delta} n}{D_{n}{ }^{3}} 100
$$

Where $\mathrm{P}_{0 \mathrm{i}}$ is initial porosity in the sector $\mathrm{i}, \mathrm{D}_{\mathrm{n}}$ is the nominal diameter, $\mathrm{n}$ is number of layer, $\mathrm{A}_{\mathrm{i}}$ is the area of the sector $i$ and $\mathrm{K}_{\Delta}$ is the layer coefficient.

In single-layer systems, $\mathrm{n}=1$ and $\mathrm{K}_{\Delta}=1$, finally:

$$
D_{i}=\frac{N_{i} D_{n}^{2}}{A_{i}\left(1-P_{0 i}\right)} 100
$$

The relation between damage and mean porosity (emerged and submerged zone) was shown in Figure 12. There is a large dispersion due to three effects:

- Different initial porosity

- Count of the pieces fallen between neighbors sectors

- Mean porosity between emerged and submerged zone 


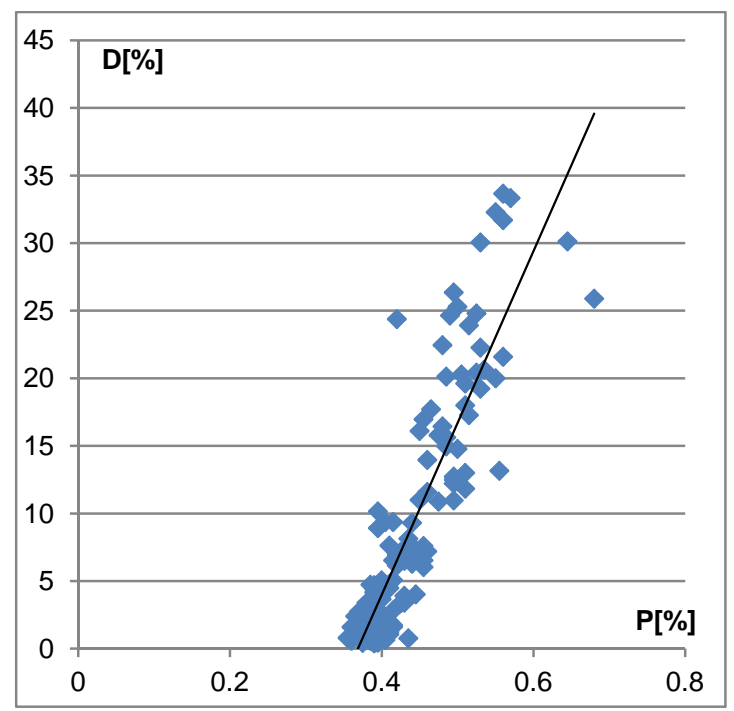

Figure 12. Relation porosity (P[\%]) versus damage (D[\%]).

In the cases of no damage or nearly, the dispersion it is consequence of the different initial porosity in the models construction. The others points scattered are due to the other two phenomena. It was concluded that porosity doesn't allow analyzing correctly the damage, because the same value of D [\%] could be represented by different values of porosity.

\section{Active zone}

The active zone was measured in two dimensions, vertical and sectorial. First of all, it was measured through the parameter "final wave height tested $\left(\mathrm{H}_{\mathrm{sf}}[\mathrm{cm}]\right)$ " for each roundhead. It was observed a concentration of damage in the roundhead, Figure 13.

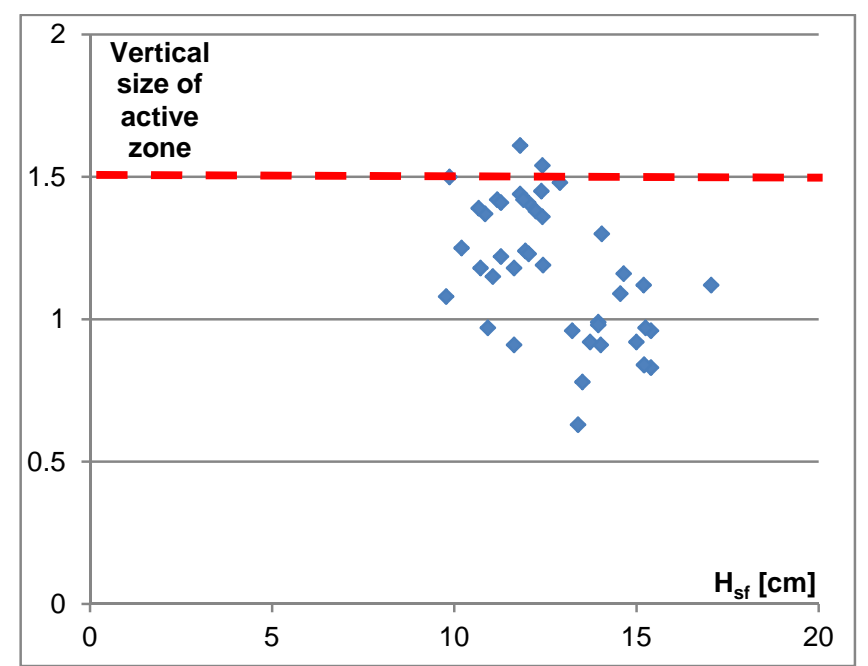

Figure 13. Vertical size of the active zone versus final wave height tested $\left(\mathrm{H}_{\mathrm{sf}}[\mathrm{cm}]\right)$ in all the roundhead.

When the final wave height increases the vertical size of the active zone reduces. This phenomenon could be possible for two possible reasons: the radius of roundhead at SWL and wave steepness.

It was concluded that radius is not relevant parameter to fix active zone, because the same radius have different vertical size of the active zone. Nevertheless it has been found that the parameter that defines the vertical size of the active zone is related to $\mathrm{s}_{\mathrm{pr}}$.

The Figure 14 shows two relations between wave steepness, with vertical size of the active zone in the left, and with the final wave height in the right. It was observed a reduction in vertical size when the $\mathrm{S}_{\mathrm{pr}}$ increases. 

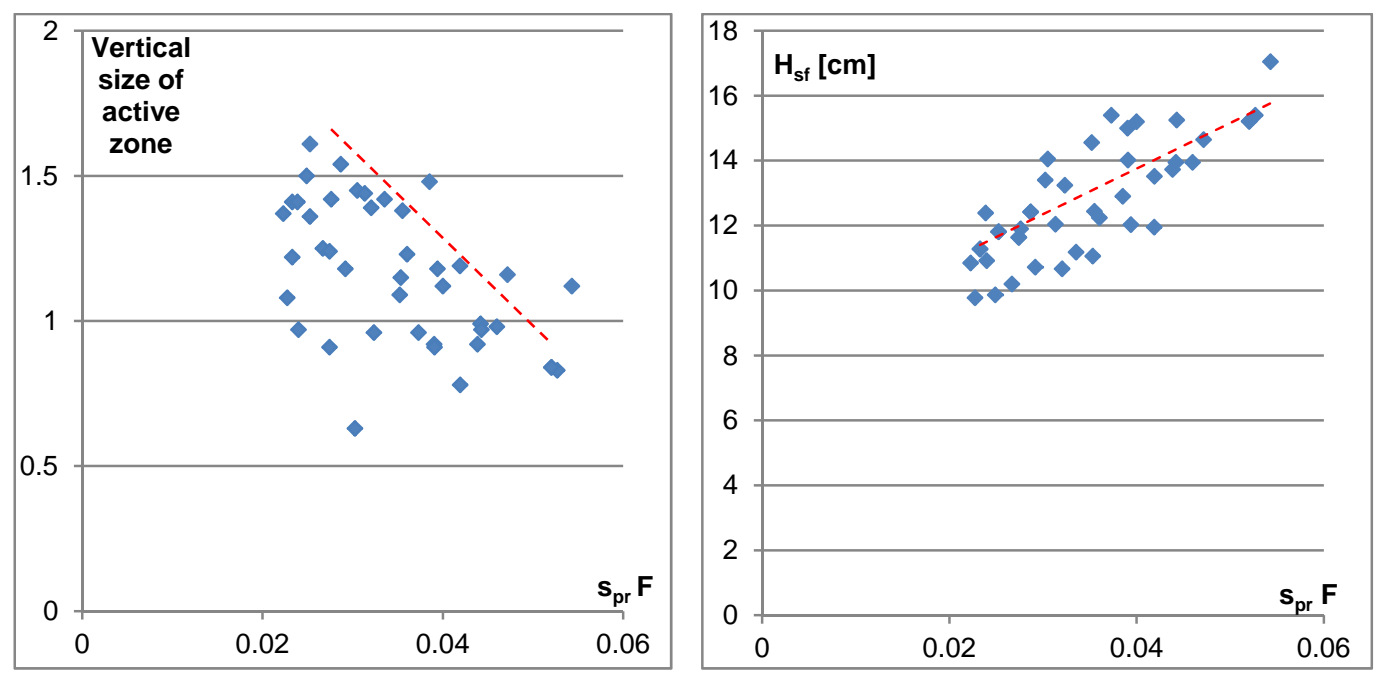

Figure 14. Left: Wave steepness $\left(s_{p r} F\right)$ versus vertical size of active zone. Right: Wave steepness $\left(s_{p r} F\right)$ versus final wave height tested $\left(\mathrm{H}_{\mathrm{st}}[\mathrm{cm}]\right)$.

As the wave steepness increases, the wave has less energy, and produces less damage in the roundhead and like consequence the vertical size of the active zone is minor. It could be possible define it in $\pm 1.5 \mathrm{H}_{\mathrm{s}}$ from the $\mathrm{SWL}$ due to the percentile $5 \%$.

The damage was measured in all the wave steps tested in all the sectors. It was concluded that the most damage sector is $90-135^{\circ}$ for all the roundhead tested, thus, it is defined like critical sector. Figure 15 shows the comparison between damage in each sector with the critical sector.

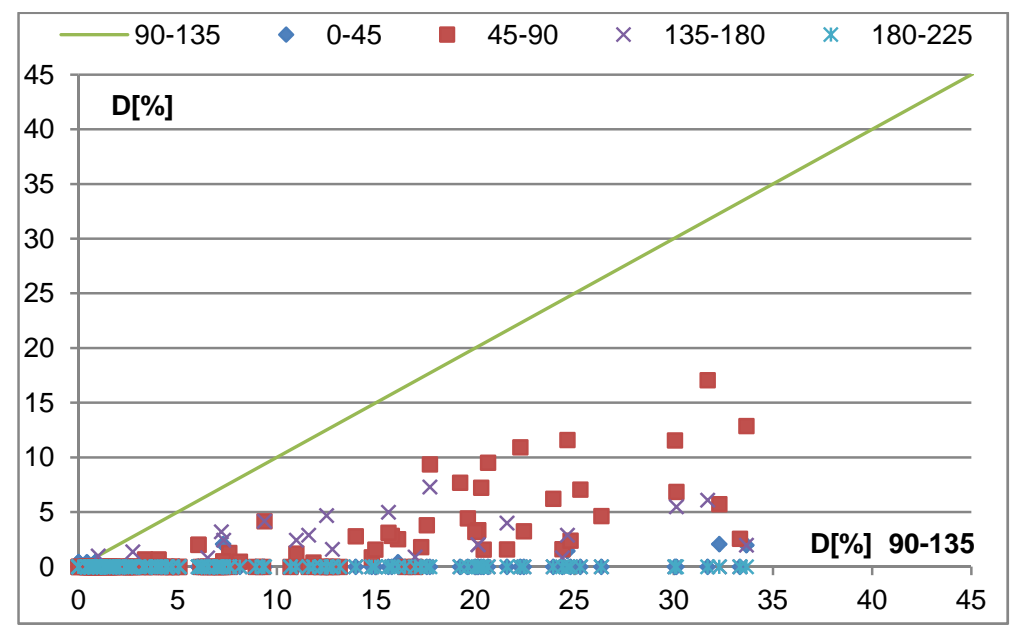

Figure 15. Sectorial damage comparison.

It was observed that sectors $45-90^{\circ}$ and $135-180^{\circ}$ have minor damage than critical but more damage than the others. In addition, the sector $180-225^{\circ}$ doesn't have damage in the entire test. Damage in $45-90^{\circ}$ it bigger than $135-180^{\circ}$, it shows that it more possible that damage moves to upstream in the roundhead armored with single-layer of Cubipods.

It was proved the influence of dimensionless parameters relatives to roundhead size in the $45-90^{\circ}$ and $135-180^{\circ}$ damage distribution. It can be verified that damage reduces according to the value of $R / L_{r p}$ (where $L_{r p}$ is the wave length at the roundhead), $R / H$ and $R_{n}$ increases:

\begin{tabular}{|c|c|c|c|c|}
\hline \multicolumn{5}{|c|}{ Table 1. Damage sector limitation according to relative size of the roundhead } \\
\hline \multirow{3}{*}{ Sector } & $\mathbf{D}[\%]$ & $\mathbf{R}_{\mathbf{n}}$ & $\mathbf{R} / \mathbf{H}$ & $\mathbf{R} / \mathbf{L}_{\mathbf{r p}}$ \\
\hline \multirow{3}{*}{$45-90^{\circ}$} & $<5$ & $>28$ & $>9$ & $>0.3$ \\
\cline { 2 - 5 } & $<10$ & $>25$ & $>6.5$ & $>0.3$ \\
\cline { 2 - 5 } & $<15$ & $>15$ & $>4.5$ & $>0.2$ \\
\hline \multirow{2}{*}{$135-180^{\circ}$} & $<5$ & $>18$ & $>6.5$ & $>0.2$ \\
\cline { 2 - 5 } & 10 & \multicolumn{4}{|c}{ It isn't produced } \\
\hline
\end{tabular}




\section{Level of damage}

Stages of damage in single layer armor are not clearly defined. The CEM (2002) and CIRIA/CUR/CETMEF (2007) show different values for double armor layer. After the quantify damage and analyzed its evolution 2 points of level of damage were defined (start of damage and failure).

1. Start of damage produces when the first piece is fallen

2. Failure produces when the filter is eroded
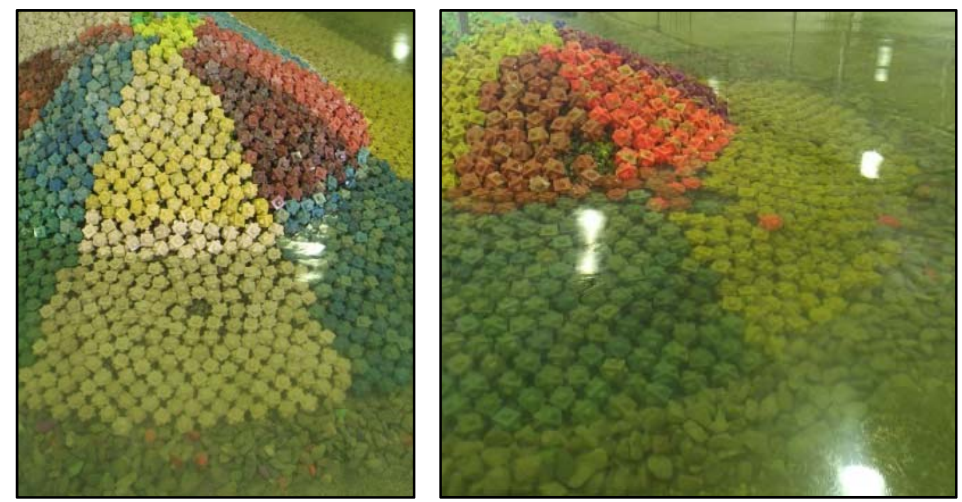

Figure 16. Left: Start of damage. Right: Failure.

It was quantified the value of damage in each level for all the roundheads and it is proposed to use the percentile $5 \%$ like the representative value:

- $\quad$ Start of damage $\rightarrow \mathrm{D}[\%]=0.4$

- $\quad$ Failure $\rightarrow \mathrm{D}[\%]=10.9$

\section{Reserve of stability}

The difference between these 2 levels of damage it has been measure, in order to know the reserve of stability. It is defined like the percentage of wave that the roundhead is able to resists since produces the start of damage until the failure.

Due to single layer armors have a more rigid behavior than the double layer, which has normally a reserve stability of $25 \%$. Thus, it is necessary to determine this evolution to quantify this effect.

$$
R E=\frac{N_{s f}-N_{s s}}{N_{s s}}
$$

Where $\mathrm{N}_{\mathrm{sf}}$ is the stability number in the failure and $\mathrm{N}_{\mathrm{ss}}$ is the stability number in the start of damage.

It was observed a great difference between all the roundhead. Except one of the test made the reserve of stability are in RE [\%] $=10$ (Figure 17 left). Just as before, it is proposed the value of percentile $5 \%$ like the representative of the single-layer roundhead armors with Cubipods, and it is $\mathrm{RE}_{\mathrm{P} 5 \%}[\%]=9$.

It was concluded that the wave steepness is the parameter involved in the behavior of this variable. In addition, the reserve of stability reduces when the $s_{\mathrm{pr}}$ increases (Figure 17 right). 

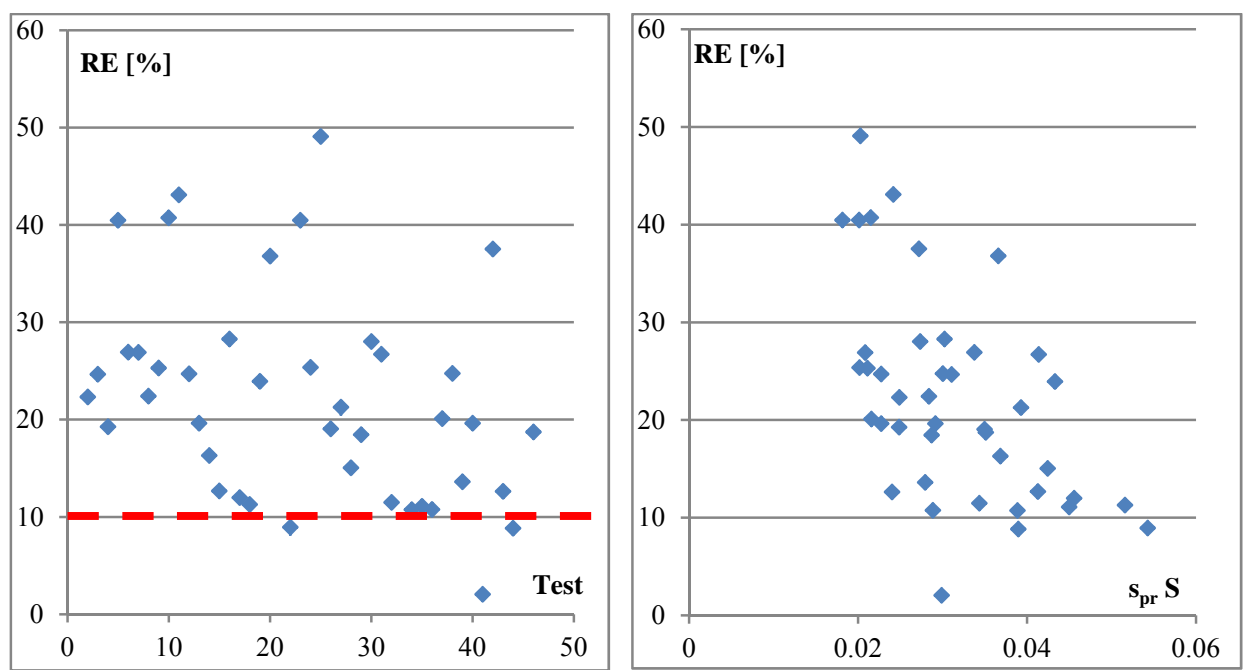

Figure 17. Left: stability reserve versus radius at SWL. Right: Relation between wave steepness in start of damage $\left(\mathrm{s}_{\mathrm{pr}} \mathrm{S}\right)$ and the stability reserve (RE [\%]).

\section{CONCLUSIONS}

The experimental campaign was concluded that critical sector is $90-135^{\circ}$ as equal of the CEM (2002) explains. The Cubipod fallen in $45-90^{\circ}$ and $135-180^{\circ}$ are consequence of the lateral lost support by the evolution of damage. In addition, the number of pieces fallen in $45-90^{\circ}$ are bigger than $135-180^{\circ}$.

Damage distribution in $45-90^{\circ}$ and $135-180^{\circ}$ are determinate for the dimensionless parameters relatives to roundhead size $\left(R / L_{r p}, R / H\right.$ and $\left.R_{n}\right)$. It can be verified that damage reduces when the value of these parameters increases.

The evolution of damage has a homogenous behavior in the entire test and it would be possible to define three phases. Initially the first Cubipods fallen are located in the submerged zone of the roundhead, then, the Cubipods of the emerged zone move to submerged zone in order to refill the holes generated previously. Finally, the failure occurs in the emerged zone when the filter is eroded.

It was proved that one piece could move more than $1 \mathrm{D}_{\mathrm{n}}$ and continue support stability. In addition, the definition of one piece displaced is when it moves to second layer or out of its collocation sector. All the movements were located in the active zone, in which the wave steepness is the parameter more involved in its vertical size. Besides, it is possible to conclude that it is $\pm 1.5 \mathrm{H}_{\mathrm{s}}$.

Damage was quantified with the volumetric parameter D [\%] in the active zone due to the relation between the number of pieces moved and the initial units.

The evolution of porosity in the emerged zone always increased, but in the submerged zone, depends on the case. This it is increased or decreased due to the moves of Cubipods in the second phase of the damage evolution. Besides, it is concluded that this phenomena is random, being not possible defined when it occurs.

It is proposed two levels of damage, start of damage and failure. The first one is defined when the first Cubipod move out of the armor, and it was quantify with a percentile $5 \%$, in $\mathrm{D}_{\mathrm{P} 5 \%}[\%]=0.4$. The second is defined at the moment to the filter erosion, $\mathrm{D}_{\mathrm{P} 5 \%}[\%]=11 \%$.

Finally, the reserve of stability defines the rigid behavior of roundhead due to the percentage of wave height between start of damage and failure. The value, with a percentile $5 \%$ is $R E_{\mathrm{P} 5 \%}[\%]=9 \%$. It was concluded that wave steepness conditions the behavior of this parameter, when it increased the reserve is reduces.

\section{ACKNOWLEDGMENTS}

SATO (OHL Group) and Universitat Politècnica de València, Laboratory of Ports and Coasts.

\section{REFERENCES}

Berenguer, J. M., \& Baonza, A. (1999). Experimental research on hollowed cubes for breakwater protection. Proceedings of the International Conference of Coastal Structures. 1, 255-262.

Besley, P., Denechere, M., Besley, P., Manager, G., Wallingford, H. R., \& Park, H. (2009). Single layer armour systems - toe , crest and roundhead details Overtopping discharge. Proceedings of the international conference of Coasts, Marine Structures and Breakwaters (ICE). 
Burcharth, H. F., Andersen, T. L., \& Medina, J. R. (2010). Stability of Cubipod armoured roundheads in short-crested waves. A comparison between Cubipod and cube armour stability. Proceedings of $32^{\text {nd }}$ Conference on Coastal Engineering.

CEM. (2002). Coastal Enginering Manual. US. Army Corps of Engineers.

CIRIA/CUR/CETMEF. (2007). The Rock Manual. The use of rock in hydraulic engineering $\left(2^{\text {nd }}\right.$ edition). C683, CIRIA,London.

Comola, F., Lykke Andersen, T., Martinelli, L., Burcharth, H. F., \& Ruol, P. (2014). Damage pattern and damage progression on breakwater roundheads under multidirectional waves. Coastal Engineering, 83, 24-35. http://doi.org/10.1016/j.coastaleng.2013.09.004

Gomez-Martin, M. E. (2015). Análisis de la evolución de averías del manto principal de diques en tlaud formado por escolleras, cubos y Cubípodos. PhD Thesis. Universidad Politécnica de Valencia, España.

Gomez-Martin, M. E., \& Medina, J. R. (2007). Cubipod Concrete Armour Unit and Heterogeneous Packing. Proceedings of the $5^{\text {th }}$ International Conference of Coastal Structures, 140-151.

Holfland, B., \& Van Gent, M. (2016). Automatic settlement analysis of single-layer armour layers. Proceedings of the 6 th International Conference on the Application of Physical Modelling in Coastal and Port Engineering and Science.

Lomonaco, P., Vidal, C., \& Gomez-Martin, M. E. (2009). Evolution of damage on roundheads protected with Cubes and Cubipod armour units. Proceedings of the international conference of Coasts, Marine Structures and Breakwaters (ICE).

Maciñeira, E. (2005). Determinación de una fórmula para el cálculo de la estabilidad del morro de un dique en talud. Análisis de los distintos factores que intervienen. $\mathrm{PhD}$ Thesis. Universidade da Coruña, España.

Maciñeira, E., \& Burcharth, H. F. (2016). Stability of cube armoured roundheads exposed to long crested and short crested waves. Coastal Engineering, 112, 99-112.

Medina, J. R. (2001). Estimation of incident and reflected waves using simulated annealing. Journal of Waterway, Port, Coastal and Ocean Engineering, 127(4), 213-221.

Medina, J. R., \& Gómez-Martín, M. E. (2015). Manual del cubípodo. Ed: Universitat Politècnica de València.

Muttray, M., \& Reedijk, B. (2009). Design of Concrete Armour Layers. Hansa International Maritime Journal, 6, 111-118.

Puente, I., Sande, J., González, H., Peña, E., Maciñeira, E., Martínez, J., \& Arias, P. (2014). Novel image analysis approach to the terrestrial LiDAR monitoring of damage in rubble mound breakwaters. Ocean Engineering, 91, 273-280. http://doi.org/10.1016/j.oceaneng.2014.09.011

Sande, J., Peña, E., Maciñeira, E., Priegue, L., \& Gómez-Martín, M. E. (2014). Stability of Small Breakwaters Roundheads Armoured With Single-Layer Cubipod Units. Proceedings of the $3^{\text {rd }}$ IAHR Europe Congress.

Van Gent, M., \& Luis, L. (2013). Application of cubes in a single layer. Proceedings of the $6^{\text {th }}$ International Short Course/Conference on Applied Coastal Research (SCACR).

Van Gent, M., \& van der Werf, I. M. (2010). Stability of breakwater roundheads during construction. Proceedings of 32nd Conference on Coastal Engineering.

Vidal, C., Losada, M. A., \& Medina, R. (1989). Estabilidad del morro de los diques en talud. Influencia de su geometría. Revista de Obras Publicas, 1950, 887-907. 